\title{
A STUDY ON THE IMPACT OF REVERSE CULTURE SHOCK AMONG NRI STUDENT REPATRIATES
}

\section{VINOD KUMAR, AMMU SURESH, AMRITA LAKSHMI PRAKASH, ANJANA PANKAJAKSHAN PILLAI \& KRISHNA ASHOK}

Department of Commerce and Management, Amrita School of Arts \& Sciences, Amrita Vishwa Vidyapeetham, Clappana, Kollam, Kerala, India

\begin{abstract}
This study explores the re-entry adjustment experience of NRI student returnees or repatriates who have lived for a minimum of 2 years in their respective expatriate nation. It is specifically concerned with the socio-psychological problems and dilemmas that these students have faced in their own lives after returning to India. The study intents to find out how these returnee students have interpreted and have adjusted to their overseas experiences after their return. To aid this research, a concise questionnaire was prepared, which over 100 returnee students have responded. The results showed varying degrees of re-entry shock and readjustment difficulty, which could be the potential consequence of the student's own feelings of marginality and alienation. The degree of difficulty seems to have been strongly rendered by Indian culture. The result hopes to help returnee students to locate the main sources of their stress and facilitate the development of strategies for coping with reverse culture shock.

KEYWORDS: Reverse Culture Shock, NRI Student
\end{abstract}

Received: Apr 28, 2020; Accepted: May 19, 2020; Published: Jun 30, 2020; Paper Id.: IJMPERDJUN2020184

\section{INTRODUCTION}

The phenomenon of not belonging to the native culture, after spending a substantial amount of time abroad has been labeled as reverse culture shock or re-entry shock. Returning to one's homeland after spending a significant period of time overseas makes one a stranger towards their own culture. The roots of reverse culture shock can be found in the work on culture shock, since the underlying concept is quite similar. Culture shock being the parent construct of reverse culture shock is "precipitated by the anxiety that results from losing all our familiar signs and symbols of social intercourse" (Oberg, 2006, p. 142). While culture shock is defined as a form of anxiety that arise by the substitution of familiar signs and values of social interactions from the newly learned values of individual's interaction with the host culture (brown \&Holloway, 2008), reverse cultural shock is emotional and psychological stage of re-adjustment and re-entry into home culture after getting accustomed to the foreign culture.

Reverse culture shock first came into light in early 1940s with the work of Scheutz (1945) about the difficulties faced by armed forces veterans on their return to homeland.

Feelings can be similar to the adjustment while living abroad, but the experience and intensity of shock is different for every individual, some have few concerns while others face many (Carlisle-Frank, 1992).

It is believed that the adjustment in the host culture and readjustment in home culture work in opposition to each other. The more successful an individual is in foreign culture, the more difficult it will be to adjust back to the 
home culture. Sussman (1986) identified that individuals who have not well adjusted and adapted in the host country experience less reverse culture shock than those individuals who have easily blended in the new culture. Sojourners experience reentry in different ways; some individuals may experience few, if any, effects of reentry, while others appear to have problems ranging from a few months to a year or longer(Adler, 1981; Carlisle-Frank, 1992).

\section{LITREATURE REVIEW}

Kalervo Oberg in 1950, introduced term 'culture shock' for the emotional distress caused by a foreign culture. This individual distress is brought about by encountering unexpected or perturbing differences of behavior and social viewpoint, and by difficulties in communication. Some people, amazingly, experience equal or even greater disorientation on return to their own culture, reverse culture shock a condition which shows the profundity of personality change that is brought about by adapting to a new culture.

Rogers and Ward (1993) in their study of 20 overseas-returned secondary school students, reported positive significant correlations between reentry difficulties and depression ( $\mathrm{r}=0.37)$ and anxiety ( $\mathrm{r}=0.52) .8$ Comparative studies carried out on Turkish migrant students and their "resident" peers also revealed less academic achievement and adjustment issues and significantly higher scores on depression and anxiety measures by returnee students

Adler, 1981; Church, 1982; Hannigan, 1990; Locke \&amp; Feinsod, 1982; Raschio, 1987; Zapf, 1991- It is not clear what academic and psycho-social problems college-aged returnees encounter upon reentry to their home country. Further, when problems are encountered, the degree to which they are experienced has yet to be systematically examined. Culture shock is a common phenomenon and, though it may take months to develop, it often affects travelers and people living far from home in unexpected ways.

Gullahorn and Gullahorn (1963) applied the culture shock construct to returning United States scholars. Their study, which combined interview and survey data of 5300 returning scholars, suggested that the reverse culture shock pattern of adjustment was similar to the U-curve of adjustment introduced by Lysgaard (1955) to describe initial culture shock adjustment; hence their introduction of the "W-curve" hypothesis.

Kagitcibasi (1987) described the reentry experience as "de-culturation", as the returnee is caught between the two cultures of host country and home country.

Eschbach Et Al (2001) stated that change may cause stress. When people encounter a new culture and experience culture shock, change and unfamiliarity influences their own psychological adjustment and participation in a cultural environment. This psychological confusion and emotional discomfort usually causes a tremendous amount of psychological stress.

Meintel, Wielkiewicz \& Turkowski (1973 2010) have agreed that the main cause of re-entry shock is the disorientation about the changed home culture and individuals own self. While further elaborating these, the noted common difficulties include academic/work related problems, cultural identity conflict, social withdrawal, depression, anxiety, interpersonal difficulties, value confusion, disillusionment, anger, hostility, compulsive fears, helplessness, disenchantment, discrimination, and stress. 


\section{OBJECTIVE}

- To make explicit the repatriation experience and to identify the readjustment problems likely to arise on their reentry when they seek to readjust to the Indian lifestyle.

- To define factors which appear to positively or negatively influence their degree of readjustment stress.

- To suggest an alternative approach to aid understanding of the experiences of "reverse culture shock"

- To examine coping strategies used by the returnee students, whose re-entry problems differ, depending to some degree on their circumstances.

- To facilitate awareness of adaptive ways of dealing with re-entry difficulties.

\section{RESEARCH METHODOLOGY}

- For our investigation, we made use of a cross-cohort, descriptive survey to collect primary data. About 100 student repatriates have recorded their response. Respondents constituted of students belonging to Amrita Institute of Medical Sciences, Kochi.

- For secondary data, we made use of google scholar and various other websites.

\section{DATA ANALYSIS}

\section{PERCENTAGE OF RESPONDENTS FACING REVERSE CULTURE SHOCK}

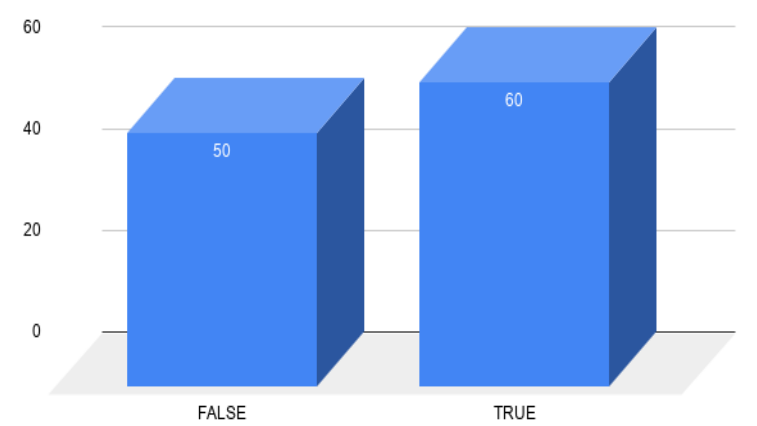

Figure 1

From the above figure, it is clear that most of the respondents from this survey is facing or have faced culture shock.

Most of the responses were "true" to the statement question asked. 


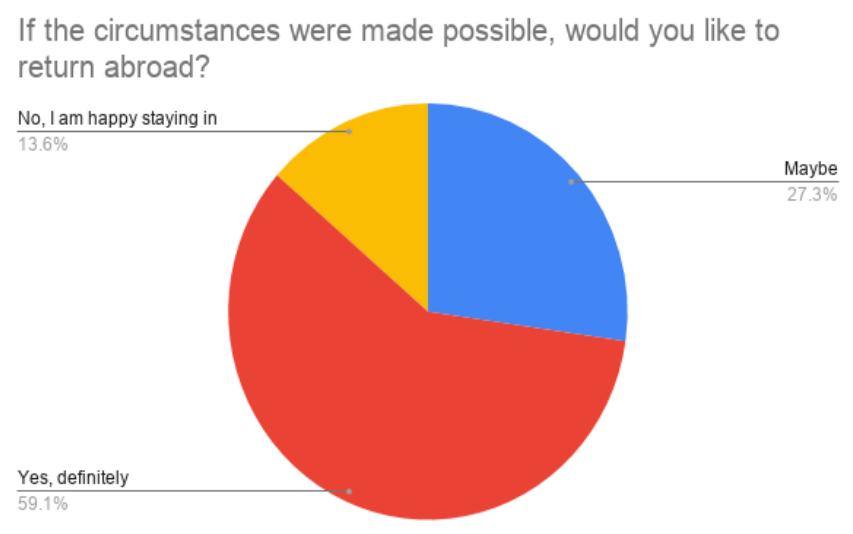

Figure 2

Most of the respondents have faced culture shock to the extent where they would like to go back.

$13 \%$ of the respondents are happy staying back in India because they have already adapted to the changes that they have encountered.



Figure 3

From the above it can be summarized that only $22.7 \%$ was depressed on their arrival to India while most of the respondents i.e. $43.6 \%$ was neutral on their impressions.

The rest $33.6 \%$ was enthusiastic on their arrival.

\section{DISCUSSIONS AND FINDINGS}

- The study proved that readjustment was a challenge for most of the students when they came back from abroad to pursue their education in India.

- It was found that most of the respondents would like to go back as they feel life is very hard here. Because they were already adapted to the foreign culture, it was hard for them to adapt to a new one because it was different to the old one.

- For some of the respondents, re-entry shock and readjustment difficulties were described as anxiety, confusion, disappointment and frustration. These problems were aggravated by feelings of marginality and heightened alienation at the discovery that they had become "strangers to their own culture." 
- Several readjustment problems were related to the home country of the returnees. The results confirm that there were unique cultural patterns that gave the expats specific readjustment problems.

- It was assumed that those who had a strong desire to remain abroad would experience greater difficulties and would be more likely to feel alienated upon re-entry. While those who had a strong desire to return home at the end of their sojourn are likely to return with a higher motivation to re-socialise.

- Majority of the respondents were found to be repatriates of GCC countries as there is an inability to afford university education and the availability of a better quality of education in India at a lower cost.

\section{CONCLUSIONS}

As for conclusion, we could say that many of the students who answered the questionnaire have experienced reverse cultural shock in some way. There are many interesting findings based on the survey data. It was found that $67 \%$ of the students have returned to India because of the quality of the educational system and $9 \%$ among them was due to parental compulsion.

Most of the respondents were shocked that the country is nothing like they expected it to be. It can be concluded that almost everyone in the survey conducted have experienced the stages of culture shock: honeymoon, frustration, adjustment and acceptance.

This study could provide a fruitful basis for future researches in this area as it has highlighted the problems faced by students on their return to their homeland in the form of reverse culture shock. The findings can be helpful for them and to those who are planning to return back home to make them aware of the feelings and behaviors that are commonly associated with reverse cultural shock.

The study identifies the issues faced, and thus provides a guide to the students to understand and learn the ways of dealing with reverse culture shock without undergoing it as the unknown and reaching a severe traumatic state.

\section{AKNOWLEDGEMENT}

Firstly, we would like to thank god almighty for guiding us throughout this project.

We thank Adv. Vinod who has let us choose such an interesting topic to do research upon and also for permitting us to submit a project on the same. We would also like to thank him for providing us with assistance and guidance throughout the project.

The completion of the project would not have been possible without the kind support and help of many individuals who spend the time and energy to provide valuable facts that had helped us in concluding this project. We would like to extend our sincere thanks to all of them.

\section{REFERENCES}

1. Gullahorn, J. T., \& Gullahorn, J. E. (1963). An extension of the U-curve hypothesis. Journal of Social Issues, 12(3), 33-47.

2. American Psychological Association. (1988). Thesaurus of psychological index terms (5th ed.). Washington, DC: Author.

3. Reverse Culture Shock in Students Returning from Overseas Kevin F. Gaw Counseling and Career Development Center University of Missouri - Rolla 
4. https://libguides.usc.edu/writing guide

5. Reverse Culture Shock: A Study of Readjustment Problems Faced by the Japanese Returnee Company-Wives by Yuki $\sim$ Shibuya

6. Pakistan Journal of Psychological Research, 2018, Vol. 33, No. 1, 257-276

7. Development of a Scale to Measure Reverse Culture Shock in Fresh Foreign Degree Holders Mubeen Akhtar, Anila Kamal, Aliya Abdul Hayee, and Sara Imtiaz Quaid-I-Azam University

8. International Journal of Intercultural Relations 24 (2000) 83 \pm 104 - Reverse culture shock in students returning from overseas Kevin F. Gaw

9. Siddiqua A Department of Psychological Medicine, Faculty of Medicine, University of Malaya, Kuala Lumpur, Malaysia

10. https://medium.com/global-perspectives/the-4-stages-of-culture-shock-a79957726164

11. Www.ccsenet.org/journal.html

12. Issundari, Sri, and Iva Rachmawati. "The Role of Citizen in Indonesian Public Diplomacy through IACS (Indonesian Arts and Cultural Scholarship) Program." International Journal of Political Science, Law and International Relations (IJPSLIR) 6.3 (2016): 1-12.

13. Khalifa, Majeed H. "Cultural Materialism Helps to Address the Relationship between Social Process and Recent Literature." International Journal of English, and Literature (IJEL) 6.1 (2016):5-10

14. Jenifer, R. Delecta, and G P Raman. "Cross Cultural Competence among Middle Management Employees in Footwear Company in China." International Journal of Business and General Management (IJBGM) 6.4 (2017):83-90

15. Chibu, Oti Robinson. "Improving Maintenance Strategy through Corporate Culture." International Journal of Business and General Management (IJBGM) 7.6 (2018):61-84

16. Rani, Poonam, and Bimla Dhanda. "Siblings Determine the Personality of Twins in Five Cultural Zones of Haryana." International Journal of Business and General Management (IJBGM) 7.5 (2018):75-80 